\title{
Human-mediated transport determines the non- native distribution of the anemone Nematostella vectensis, a dispersal-limited estuarine invertebrate
}

\author{
John A. Darling ${ }^{1, *}$, Ashley Kuenzi $^{1}{ }$, Adam M. Reitzel ${ }^{2}$ \\ ${ }^{1}$ National Exposure Research Laboratory, US Environmental Protection Agency, 26 West Martin Luther King Drive, \\ Cincinnati, Ohio 45208, USA \\ ${ }^{2}$ Woods Hole Oceanographic Institution, 266 Woods Hole Road, Woods Hole, Massachusetts 02543, USA
}

\begin{abstract}
Sessile invertebrates are common invaders of estuarine ecosystems. To expand their non-native ranges, these invasive taxa must contend with the geographically and ecologically discontinuous nature of estuarine habitats, in many cases without the benefit of highly dispersive larval phases. In addition, their population dynamics may reflect contributions from both sexual and asexual reproduction. Here we use genetic methods to explore the population structure of Nematostella vectensis, a dispersal-limited salt marsh anemone, along the Pacific coast of North America. Analysis of 9 highly polymorphic microsatellite loci reveals that asexual reproduction is critical to both maintenance of local population density and regional population expansion. While high levels of genetic differentiation among populations $\left(F_{\mathrm{ST}}>0.3\right)$ reflect general restrictions to natural dispersal, the observation of 2 clones distributed across multiple, widely separated sampling sites indicates that long distance dispersal of adult anemones is a major contributor to the spread of $N$. vectensis. We argue that anthropogenic transport represents the most likely mechanism driving this spread, although rafting may offer an alternative explanation for the observed distribution.
\end{abstract}

KEY WORDS: Nematostella vectensis · Invasive species · Clonality · Asexual reproduction · Dispersal $\cdot$ Microsatellites $\cdot$ Estuarine

Resale or republication not permitted without written consent of the publisher

\section{INTRODUCTION}

The past half century has seen a dramatic rise in the incidence and effect of aquatic biological invasions, as globalization of trade and the efficiency of international shipping and travel vastly increase opportunities for populations to disperse beyond their native range limits (Cohen \& Carlton 1998, Ruiz et al. 2000). A substantial proportion of these invasions have occurred in estuarine ecosystems, largely due to their association with common vectors of introduction such as commercial shipping and recreational boating (Wonham et al. 2000, Carlton 2001, Floerl \& Inglis 2005). The ecological consequences of estuarine invasions can be substantial (Grosholz 2002), and the associated costs in terms of lost ecosystem services may require significant investment in the management of threats posed by introduced populations (Williams \& Grosholz 2008). Understanding the population dynamics of introduced taxa is a critical prerequisite to effective management, as knowledge of life history and demographic characteristics provides important insights into the potential for dispersal to and colonization of new habitats, the likely geographic patterns of range expansion and the possible responses to novel environmental challenges (Sakai et al. 2001).

Sessile benthic invertebrates are frequent invaders of estuarine ecosystems, as they often contribute to fouling assemblages and, as a result, are prone to human-mediated transport (Carlton \& Geller 1993). However, full appreciation of the population dynamics of these taxa is complicated by 2 important aspects of their biology. First, many sessile invertebrates are capable of asexual reproduction (Jackson et al. 1985), 
and patterns of population growth and spatial expansion may reflect contributions of both sexual and asexual increase. Asexual reproduction is known to have significant effects on the population structure of reefbuilding corals (Stoddart 1984, Miller \& Ayre 2004, Whitaker 2006, Foster et al. 2007) and other anthozoans (Ayre 1984, Shaw 1991, Sherman \& Ayre 2008), as well as some other invertebrate taxa (Zilberberg et al. 2006). However, the potential effect of reproductive plasticity on invasion dynamics in marine invertebrate taxa remains understudied. Second, estuaries are discrete habitats, typically separated by both geographic and ecophysiological boundaries, and dispersal between these habitats depends on complex hydrological, physiological and behavioral mechanisms (Bilton et al. 2002). Differences in larval strategies (i.e. larval retention versus larval dispersal) can result in widely differing patterns of genetic connectivity between estuaries, with corresponding implications for evolutionary diversification and range expansion (Bilton et al. 2002, Levin 2006).

The salt marsh anemone Nematostella vectensis Stephenson, 1935 provides a promising system within which to examine the interactions of reproductive plasticity and dispersal on the population dynamics of an introduced estuarine species. Recent genetic evidence indicates that $N$. vectensis has been introduced to both England and the west coast of the USA from its presumed native range in the northwestern Atlantic Ocean (Reitzel et al. 2008). The species is capable of asexual reproduction through either physal pinching, in which an aboral fragment of the adult anemone is cleaved off and subsequently develops new head structures, or polarity reversal, in which the adult develops a new oral crown at its aboral pole before undergoing cleavage through the body column (Reitzel et al. 2007). Both of these mechanisms involve transverse fission of the adult anemone, and it is likely that both are important to the maintenance of population density in natural populations (Darling et al. 2004, Reitzel et al. 2008). Although a high frequency of anemones undergoing polarity reversal (i.e. 2-headed anemones) have been observed in some wild populations, physal pinching is clearly the predominant form of asexual reproduction in laboratory populations (Reitzel et al. 2008). In addition, genetic and experimental studies suggest that $N$. vectensis possesses extremely low dispersal capacity, even at spatial scales of tens of meters (Stocks \& Grassle 2001, Darling et al. 2004). This is despite the fact that development proceeds through a ciliated planula stage capable of active swimming for up to $14 \mathrm{~d}$ in culture (Hand \& Uhlinger 1992). The observed limitations on dispersal may be related to either behavioral or physical restrictions on the access of planulae to the open ocean (Bil- ton et al. 2002); regardless, they suggest that natural colonization of geographically distant sites should be rare.

Here we use genetic data to investigate the contributions of both clonal reproduction and long distance dispersal to the regional expansion of Nematostella vectensis on the Pacific coast of North America. We examine 7 populations throughout the known range of $N$. vectensis in this region, and use 9 highly polymorphic microsatellite loci to assess (1) the prevalence of asexual reproduction based on the observation of repeated multilocus genotypes (MLGs), (2) genetic connectivity between populations, and (3) the spatial extent of clonal genotypes. Our findings suggest that the expansion of $N$. vectensis in the northeastern Pacific Ocean has probably been driven primarily, if not entirely, by human dispersal vectors. The contribution of these vectors to contemporary patterns of genetic diversity observed in this species may have implications for the expected genetic patterns in other invasive estuarine invertebrates with facultative asexual life histories.

\section{MATERIALS AND METHODS}

Sample collection. Adult Nematostella vectensis were collected from throughout the species' known range on the Pacific coast of North America, using methods described previously by Darling et al. (2004). Additional attempts to sample anemones south of San Francisco Bay were unsuccessful, which is consistent with a lack of reports on $N$. vectensis presence in southern California. The distribution of the species observed in the present study is consistent with previous observations (Hand \& Uhlinger 1994); in addition to being restricted to estuarine habitats with soft substrates, the species does not appear to be continuously distributed throughout suitable habitat in the northeast Pacific Ocean.

Molecular methods. Samples were either preserved in $95 \%$ ethanol or returned alive to the laboratory, where they were maintained in one-third strength (salinity 13) artificial seawater. In most cases, a fragment of tissue approximately $2 \mathrm{~mm}$ long was removed from the pedal end of each individual, and whole genomic DNA was extracted using the Qiagen DNeasy Tissue Kit (Qiagen) according to manufacturer's instructions. In the case of very small individuals, the entire specimen was processed for DNA.

Microsatellite loci Nv4, Nv8, Nv13, Nv16, Nv17, Nv24, and Nv29 were amplified according to protocols described in Darling et al. (2006). Each $15 \mu \mathrm{l}$ PCR contained 0.5 U Taq DNA polymerase (Invitrogen), $1 \times \mathrm{Mg}$ free PCR buffer, $1 \mu \mathrm{M}$ each forward and reverse primer 
(for $N v 17$ only $0.1 \mu \mathrm{M}$ of each primer was used), $0.67 \mathrm{mM}$ dNTPs, $1.7 \mathrm{mM} \mathrm{MgCl}_{2}$, and approximately $5 \mathrm{ng}$ of DNA template. Cycling parameters consisted of $5 \mathrm{~min}$ at $94^{\circ} \mathrm{C}$ followed by 35 cycles of $1 \mathrm{~min}$ at $94^{\circ} \mathrm{C}$, $1 \mathrm{~min}$ at the locus-specific annealing temperature, and $1 \mathrm{~min}$ at $72^{\circ} \mathrm{C}$, with a final 15 min extension step at $72^{\circ} \mathrm{C}$. Amplified products were diluted with Hi-Di formamide and sized on an ABI 3730 DNA analyzer (Applied Biosystems). Microsatellite data was scored using Genemarker v1.70 software (SoftGenetics).

Data analysis. Distinct multilocus genotypes (MLGs) were identified and assigned to clones using GENCLONE (Arnaud-Haond \& Belkhir 2007). In addition, this software was used to calculate $p_{\text {gen }}$, the probability of each MLG arising through sexual recombination given observed allele frequencies. When multiple (n) instances of the same MLG were observed, we also calculated $p_{\text {sex }}$, the probability of $n$ occurrences of that MLG arising through independent instances of sexual reproduction. Departures from Hardy-Weinberg equilibrium were allowed, and each value was calculated both across the entire region and within individual populations. To assess the spatial extent of clonal genotypes, we determined the probability of clonal identity within 4 distance classes. The maximum spatial extent of these 4 classes was, respectively, $0 \mathrm{~km}$ (within individual collection sites), $477 \mathrm{~km}$ (inclusive of single collection sites and their nearest neighbors), $837 \mathrm{~km}$ (inclusive of the 2 nearest neighbors of each site), and $1627 \mathrm{~km}$ (all collection sites). Distances were measured in kilometers along the coast in ArcView GIS v9.1 (ESRI). Genotypic richness $(R)$, Simpson's diversity index $(D)$, and Simpson's evenness index $\left(E_{\mathrm{D}}\right)$ were calculated for each population in GENCLONE, and allelic richness $(A)$ and expected heterozygosity $\left(H_{\mathrm{E}}\right)$ were calculated in FSTAT v2.9.3 (Goudet 2001).

To determine the degree of genetic differentiation between populations, we calculated pairwise $F_{\text {ST }}$ values using GENEPOP v4.0 (Rousset 2008), with 1000 bootstrap replicates to assess statistical support. To visualize genetic relationships among Nematostella vectensis populations, we employed 3-dimensional factorial correspondence analysis in GENETIX v4.0.5 (Belkhir et al. 2004). Since the presence of repeated MLGs can significantly affect the results of these analyses, we conducted them on both an unedited dataset and a truncated dataset in which every MLG within each population was counted only once; in other words, repeated instances of single MLGs were removed from individual populations but retained in separate populations. While the most meaningful analysis of population structure is probably the one based on allele frequencies calculated from unique MLGs, we include the unedited analysis for comparison.

\section{RESULTS}

\section{Genetic diversity within populations}

Genetic diversity measures varied widely between populations (Table 1). Repeated MLGs were observed in all samples, but the proportion of the most common genotype and the genotypic richness differed dramatically. Coos Bay (CB) had the most genotypically diverse population observed $(R=0.2889, D=0.8415)$, but even this population was dominated by a single MLG representing $28 \%$ of all individuals. In the most extreme case, the population from San Juan Island (SJI) in Puget Sound consisted of only 3 MLGs $(R=$ $0.1250, D=0.4706$ ), with the most common one comprising over $70 \%$ of the sample. Although most MLGs observed occurred as singletons (Fig. 1), these comprised only a small proportion of the total dataset (approximately $8 \%$; Table 2 ) due to the high frequency of occurrence of a number of clones.

With only 2 exceptions, all repeated MLGs could be attributed confidently to asexual reproduction (Table $2)$. In the case of the most common MLG from Humboldt Bay (HB) (Clone 1), we could not reject the possibility that the number of observed individuals with

Table 1. Nematostella vectensis. Summary of collection sites on the US Pacific coast and genetic diversity measures. $\mathrm{N}=$ sample size; $G=$ num-

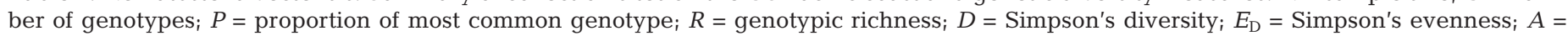
Allelic richness; $H_{\mathrm{E}}=$ expected heterozygosity. Latitude and longitude are given in decimal degrees; see Fig. 2 for map of locations

\begin{tabular}{|llcccccccccc}
\hline Sample & Location & Latitude & Longitude & $N$ & $G$ & $P$ & $R$ & $D$ & $E_{\mathrm{D}}$ & $A$ & $H_{\mathrm{E}}$ \\
\hline SJI & San Juan Island, Washington & 48.504494 & -122.898981 & 17 & 3 & 0.71 & 0.1250 & 0.4706 & 0.5051 & 1.8701 & 0.4016 \\
GH & Gray's Harbor, Washington & 46.953151 & -124.058762 & 18 & 5 & 0.33 & 0.2353 & 0.7974 & 0.8876 & 2.5770 & 0.4044 \\
WB & Willapa Bay, Washington & 46.559184 & -123.938433 & 41 & 7 & 0.32 & 0.1500 & 0.8073 & 0.8821 & 2.7294 & 0.4864 \\
YB & Yaquina Bay, Oregon & 44.621459 & -124.033935 & 33 & 7 & 0.61 & 0.1875 & 0.6136 & 0.5074 & 2.6423 & 0.4486 \\
CB & Coos Bay, Oregon & 46.953151 & -124.058762 & 46 & 14 & 0.28 & 0.2889 & 0.8415 & 0.7656 & 3.1486 & 0.5178 \\
HB & Humboldt Bay, California & 40.769651 & -124.206431 & 26 & 3 & 0.50 & 0.0800 & 0.5569 & 0.7486 & 1.8746 & 0.4200 \\
TB & Tomales Bay, California & 38.166395 & -122.907986 & 9 & 4 & 0.33 & 0.3750 & 0.8056 & 0.8533 & 2.6250 & 0.5470 \\
& & & & & & & & & & & \\
\hline
\end{tabular}




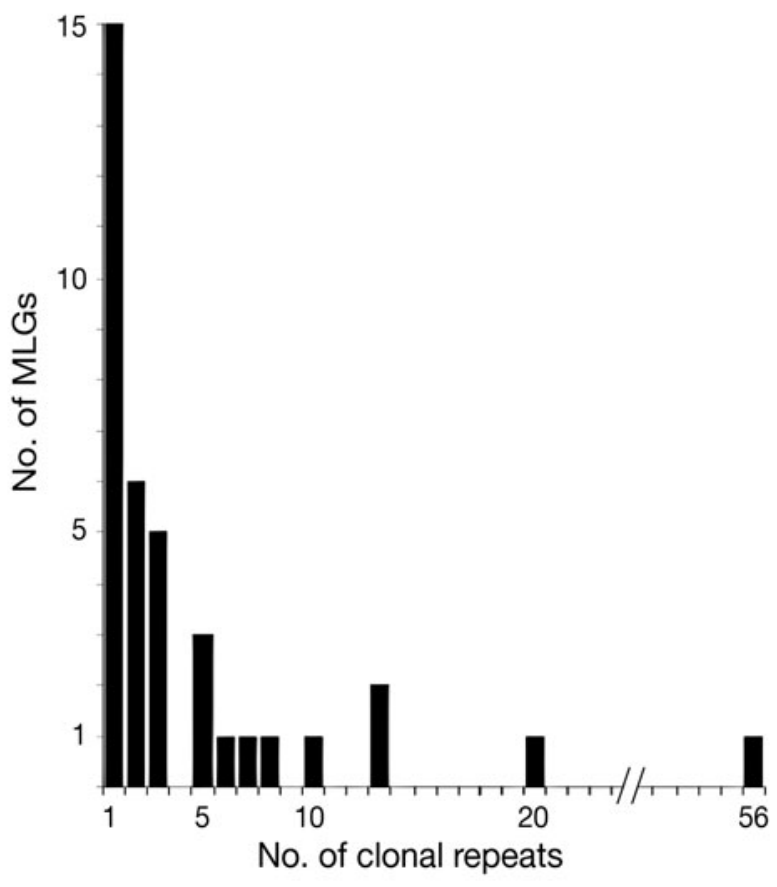

Fig. 1. Nematostella vectensis. Frequency distribution of distinct multilocus genotypes (MLGs) the same genotype may have arisen through sexual recombination $\left(\mathrm{p}_{\mathrm{sex}}=0.4435\right)$. The same held true for one MLG observed 4 times in the San Juan Islands $\left(p_{\text {sex }}=0.1833\right)$. These somewhat counterintuitive results can be attributed to the extremely limited allelic diversity in these populations $(A=1.8746$ for $\mathrm{HB}, A=1.8701$ for $\mathrm{SJI}$ ), which renders the occurrence of the observed MLGs likely even when alleles are recombined randomly. In all other cases, $p_{\text {sex }}$ for repeated MLGs within populations was less than $\alpha=$ 0.05 , and the hypothesis of sexual reproduction was rejected.

\section{Spatial extent of clones}

Two MLGs were shared between multiple populations (Table 2 \& Fig. 2). The most common of these (Clone 1) was observed in 4 populations (SJI, Yaquina Bay [YB], CB, HB), and comprised nearly $30 \%$ of the entire dataset; the second (Clone 2) was found at SJI, $\mathrm{CB}, \mathrm{HB}$, and Tomales Bay (TB), and represented approximately $11 \%$ of all individuals. The geographic extent of these single clones was broad, with Clone 2

Table 2. Nematostella vectensis. Clonal diversity. Individual clones extending across multiple collection sites are highlighted in gray. $\mathrm{p}_{\mathrm{gen}}=$ likelihood of individual genotype arising through sexual reproduction, given allelic frequencies in the regional population; $\mathrm{p}_{\mathrm{sex}}=$ likelihood of obtaining the total number of observations of the same genotype in the regional population, given allelic frequencies; $\mathrm{ns}=$ repeated genotypes with non-significant values of $\mathrm{p}_{\mathrm{sex}}(>0.05)$ within individual samples; na $=$ not applicable. See Table 1 for definition (location) of sample abbreviations

\begin{tabular}{|c|c|c|c|c|c|c|c|c|c|c|c|}
\hline \multirow[t]{2}{*}{ Clone } & \multirow[b]{2}{*}{ SJI } & \multicolumn{3}{|c|}{ - Population } & \multirow[b]{2}{*}{$\mathrm{CB}$} & \multirow[b]{2}{*}{ HB } & \multirow[b]{2}{*}{ TB } & \multirow[t]{2}{*}{ Count } & \multirow[t]{2}{*}{ Frequency } & \multirow{2}{*}{$p_{\text {gen }}$} & \multirow{2}{*}{$\mathrm{p}_{\text {sex }}$} \\
\hline & & $\mathrm{GH}$ & WB & YB & & & & & & & \\
\hline 1 & 12 & & & 20 & 11 & $13 \mathrm{~ns}$ & & 56 & 0.294737 & 0.000214 & 3.71E-154 \\
\hline 2 & $4 \mathrm{~ns}$ & & & & 1 & 12 & 3 & 20 & 0.105263 & $5.79 \mathrm{E}-05$ & $1.94 \mathrm{E}-55$ \\
\hline 3 & & & 13 & & & & & 13 & 0.068421 & $6.77 \mathrm{E}-10$ & 3.03E-92 \\
\hline 4 & & & & & 13 & & & 13 & 0.068421 & $2.08 \mathrm{E}-05$ & $2.15 E-38$ \\
\hline 5 & & & 10 & & & & & 10 & 0.052632 & $1.47 \mathrm{E}-08$ & $2.33 \mathrm{E}-56$ \\
\hline 6 & & & & & 8 & & & 8 & 0.042105 & $1.14 \mathrm{E}-06$ & $3.87 E-30$ \\
\hline 7 & & & 7 & & & & & 7 & 0.036842 & $3.55 \mathrm{E}-07$ & $1.21 \mathrm{E}-28$ \\
\hline 8 & & 6 & & & & & & 6 & 0.031579 & $3.51 \mathrm{E}-08$ & $1.04 \mathrm{E}-28$ \\
\hline 9 & & & 5 & & & & & 5 & 0.026316 & $1.64 \mathrm{E}-08$ & $3.79 \mathrm{E}-24$ \\
\hline 10 & & & & 5 & & & & 5 & 0.026316 & $3.51 \mathrm{E}-05$ & $7.96 \mathrm{E}-11$ \\
\hline 11 & & 5 & & & & & & 5 & 0.026316 & $3.67 \mathrm{E}-06$ & $9.49 \mathrm{E}-15$ \\
\hline 12 & & & & & & & 3 & 3 & 0.015789 & $5.01 \mathrm{E}-07$ & $4.51 \mathrm{E}-09$ \\
\hline 13 & & & 3 & & & & & 3 & 0.015789 & $8.20 \mathrm{E}-11$ & $1.21 \mathrm{E}-16$ \\
\hline 14 & & 3 & & & & & & 3 & 0.015789 & $2.85 \mathrm{E}-07$ & $1.46 \mathrm{E}-09$ \\
\hline 15 & & & & 3 & & & & 3 & 0.015789 & $1.97 \mathrm{E}-07$ & $6.93 \mathrm{E}-10$ \\
\hline 16 & & 3 & & & & & & 3 & 0.015789 & $1.30 \mathrm{E}-07$ & $3.02 \mathrm{E}-10$ \\
\hline 17 & & & & & & & 2 & 2 & 0.010526 & $4.36 \mathrm{E}-09$ & $8.28 \mathrm{E}-07$ \\
\hline 18 & & & & & 2 & & & 2 & 0.010526 & $1.70 \mathrm{E}-08$ & $3.22 \mathrm{E}-06$ \\
\hline 19 & & & 2 & & & & & 2 & 0.010526 & $1.78 \mathrm{E}-09$ & $3.38 \mathrm{E}-07$ \\
\hline 20 & & & & & 2 & & & 2 & 0.010526 & $1.88 \mathrm{E}-08$ & $3.57 \mathrm{E}-06$ \\
\hline 21 & & & & & 2 & & & 2 & 0.010526 & $2.92 \mathrm{E}-06$ & 0.000555 \\
\hline 22 & & & & 2 & & & & 2 & 0.010526 & $4.08 \mathrm{E}-08$ & $7.75 \mathrm{E}-06$ \\
\hline Singletons & 1 & 1 & 1 & 3 & 7 & 1 & 1 & 15 & 0.078947 & na & na \\
\hline Total & 17 & 18 & 41 & 33 & 46 & 26 & 9 & 190 & & & \\
\hline
\end{tabular}




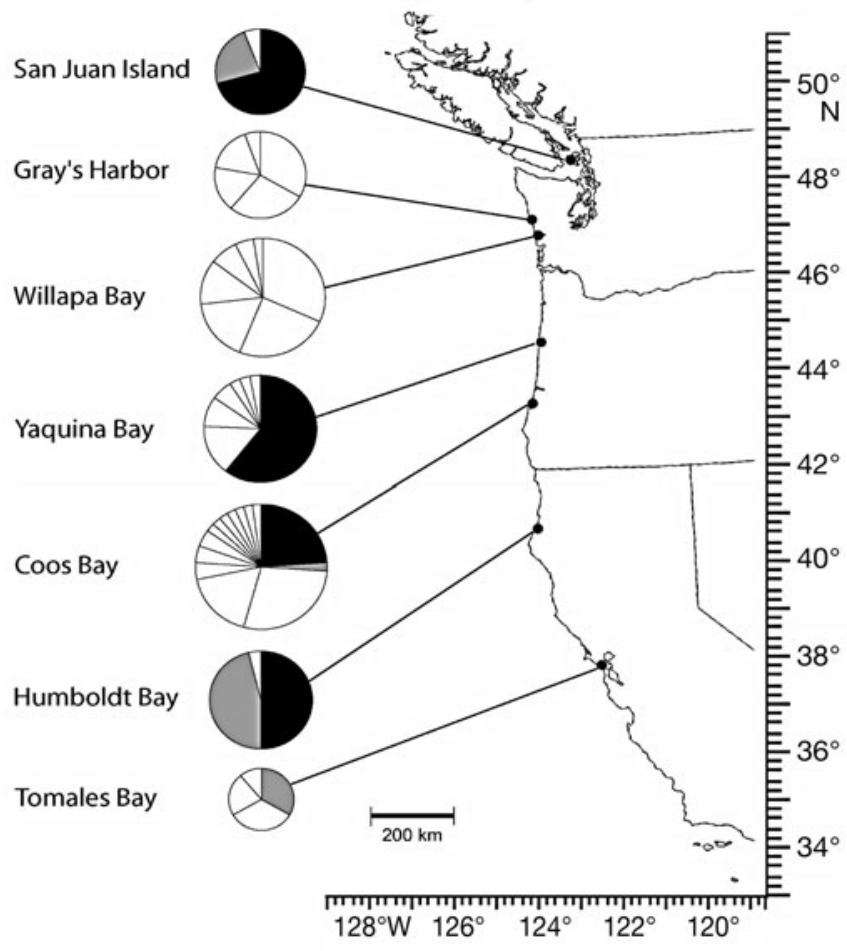

Fig. 2. Nematostella vectensis. Geographic distribution of clones. Pie graphs are scaled to sample size; pie graph segments indicate relative frequency of MLGs observed at each collection site. Shared Clones 1 and 2 are shown in black and gray, respectively; all private clones are shown in white. Approximate west longitude and north latitude are shown on $x$ - and $y$-axes, respectively

Table 3. Nematostella vectensis. Clonal subrange analysis. Distance classes are defined as described in 'Materials and methods'. $\mathrm{p}=$ probability of 2 individuals drawn from within the distance class having the same MLG

\begin{tabular}{|lcccc|}
\hline $\begin{array}{l}\text { Distance } \\
\text { class }\end{array}$ & $\begin{array}{c}\text { Minimum } \\
\text { distance }\end{array}$ & $\begin{array}{c}\text { Average } \\
\text { distance }\end{array}$ & $\begin{array}{c}\text { Maximum } \\
\text { distance }\end{array}$ & $\mathrm{p}$ \\
\hline 1 & 0 & 0 & 0 & 0.2571 \\
2 & 34 & 306 & 477 & 0.0441 \\
3 & 523 & 717 & 837 & 0.1538 \\
4 & 1000 & 1214 & 1627 & 0.1519 \\
\hline
\end{tabular}

Table 4. Nematostella vectensis. Genetic differentiation between populations. Pairwise $F_{\mathrm{ST}}$ values are given for the complete dataset (below diagonal) and for the dataset with clones reduced within individual samples (see 'Materials and methods' for details). Values that are not significant ( $p>0.05$ ) are indicated in bold text. See Table 1 for definition (location) of sample abbreviations

\begin{tabular}{|ccccclcc|}
\hline & SJI & GH & \multicolumn{1}{c}{ WB } & \multicolumn{1}{c}{ YB } & \multicolumn{1}{c}{ CB } & \multicolumn{1}{c|}{ HB } & \multicolumn{1}{c|}{ TB } \\
\hline SJI & - & $\mathbf{- 0 . 1 6}$ & 0.31587 & $\mathbf{- 0 . 0 2 6 7 2}$ & $\mathbf{0 . 0 0 4 5 3}$ & 0.20293 & $\mathbf{- 0 . 0 3 1 1 5}$ \\
GH & 0.30995 & - & 0.31587 & $\mathbf{- 0 . 0 0 9 1 6}$ & $\mathbf{0 . 0 1 9 6}$ & 0.20293 & $\mathbf{- 0 . 0 4 1 2 1}$ \\
WB & 0.37376 & 0.19665 & - & 0.19675 & 0.16539 & 0.12928 & 0.2441 \\
YB & 0.00709 & 0.24249 & 0.31137 & - & $\mathbf{0 . 0 1 8 2 3}$ & 0.11159 & 0.0304 \\
CB & 0.06637 & 0.26128 & 0.26058 & 0.05274 & - & 0.15971 & $\mathbf{0 . 0 1 4 7 1}$ \\
HB & $\mathbf{- 0 . 0 2 0 2 3}$ & 0.31288 & 0.3765 & 0.02258 & 0.0713 & - & 0.16704 \\
TB & 0.07151 & 0.26791 & 0.30328 & 0.08206 & 0.05892 & 0.06075 & - \\
\hline
\end{tabular}

spread over $1627 \mathrm{~km}$ and Clone 1 over $1150 \mathrm{~km}$. Analysis of clonal subrange (Table 3 ) indicated that the likelihood of 2 randomly chosen MLGs being identical was highest within populations (distance class 1, maximum distance $=0 \mathrm{~km} ; \mathrm{p}=0.2571$ ). This likelihood declined precipitously when the subrange was increased to include each population's nearest neighbor (Class $2 ; \mathrm{p}=0.0441$ ), but rose again when the subrange was expanded to include the 2 nearest neighbors Class $3 ; \mathrm{p}=0.1583$ ) or the entire range (Class $4 ; \mathrm{p}=$ $0.1519)$.

\section{Genetic relatedness between populations}

Genetic differentiation between Nematostella vectensis populations was dramatic, as revealed by pairwise estimates of $F_{\mathrm{ST}}$. When the full dataset was considered, all pairwise comparisons were statistically significant with the exception of SJI and HB (Table 4, below diagonal). Levels of differentiation were exhigh in some cases, with $F_{\mathrm{ST}}$ values over 0.3 . ( $\left.F_{\mathrm{ST}}=0.1967\right)$. When we considered a dataset from which repeated MLGs had been removed from individual populations, $F_{\mathrm{ST}}$ values generally decreased, and a number of pairwise comparisons were no longer statistically significant (Table 4, above diagonal). The most dramatic changes were the overall reduction in differentiation between $\mathrm{GH}$ and other populations, and the increase in differentiation between SJI and HB, now statistically significant at $F_{\mathrm{ST}}=0.20293$. Notably, WB remained highly diverged from all other populations.

Factorial correspondence analysis of individual MLGs was consistent with genetic distance analysis (Fig. 3). In particular, the populations from SJI and $\mathrm{HB}$ cluster very tightly together, and $\mathrm{WB}$ and $\mathrm{GH}$ both fall far outside the diffuse cluster comprising the remaining populations. Spatial relationships between populations did not change substantially when the truncated dataset was considered, although the overall percentage of genetic variance explained by the 3 factors was reduced from 91.19 to $85.25 \%$ (not shown). 


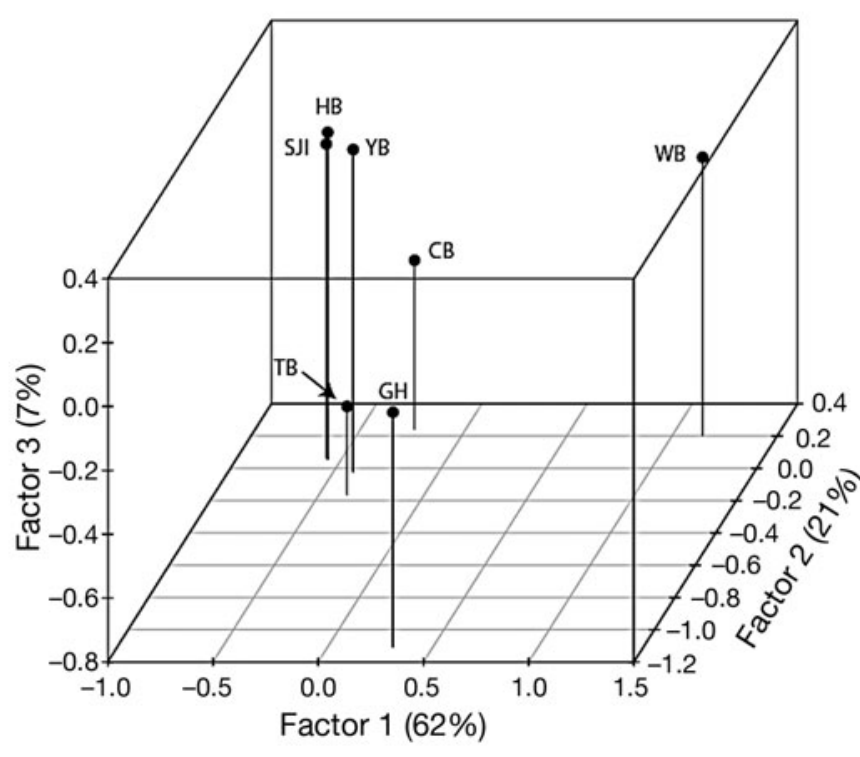

Fig. 3. Nematostella vectensis. Factorial correspondence analysis of microsatellite data. Only results from analysis of the edited dataset (unique MLGs only) are shown

\section{DISCUSSION}

\section{Asexual reproduction and colonization success of Nematostella vectensis}

Previous studies have revealed an important role for reproductive plasticity in generating the patterns of genetic variation observed in Nematostella vectensis populations (Pearson et al. 2002, Darling et al. 2004, Reitzel et al. 2008). While some populations appear to derive exclusively from sexual reproduction, others can be dominated by single MLGs to the point that at least one population has been reported consisting solely of a single clone (Darling et al. 2004). Typically, wild populations of $N$. vectensis appear to be maintained by a combination of both sexual and asexual reproduction, with clonal lineages existing in populations largely consisting of unique, sexually produced MLGs (Darling et al. 2004). However, evidence of asexual reproduction appears to be much more pronounced in those populations that have presumably been introduced by human activity (Pearson et al. 2002, Reitzel et al. 2008).

The distribution of MLGs reported here is consistent with these earlier observations. All populations possessed clonal lineages, with the dominance of single clones varying widely among populations, and all repeated MLGs could be confidently ascribed to asexual reproduction. The only clonal lineages with nonsignificant values of $\mathrm{p}_{\text {sex }}>0.05$ within individual samples were Clone 1 at Humboldt Bay and Clone 2 at San Juan Island. However, since these clones were also found widely distributed at other sites, it is unlikely that they derived from sexual recombination and is probable that the high values of $p_{\text {sex }}$ are an artifact of low allelic diversity (Table 1). Thus, although most MLGs occurred as singletons (Fig. 1), the vast majority of individuals could be assigned to clonal lineages, and only about $8 \%$ of all anemones could not confidently be attributed to asexual reproduction (Table 2).

Still, the elevated clonal diversity observed at many sites (Table 1) suggests that population density is not achieved solely through expansion of dominant clones. The relatively high frequency of unique MLGs in the populations at Coos Bay and Yaquina Bay (0.15 and 0.09, respectively) indicates that sexual reproduction contributes substantially to genetic diversity at these sites, despite the prominence of clonal genotypes. The distribution of genetic diversity at Coos Bay and Willapa Bay may similarly indicate the joint contributions of sexual and asexual reproduction. The large number of clonal lineages observed at these sites (Table 2) suggests that MLGs generated through recombination may later expand asexually, giving rise to populations with significant clonal diversity despite the presence of dominant clones. Frequent adoption of mixed asexual and sexual reproduction within single populations, observed now throughout the native and introduced ranges of Nematostella vectensis, suggests that there may be significant individual variation in response to the cues triggering reproductive decisions for this species.

The capacity to reproduce asexually has been often cited as a characteristic conducive to invasion success (Sakai et al. 2001), though the correlation has been reported most thoroughly in plant systems (Ruesink \& Collado-Vides 2006, Wright \& Davis 2006, Burns 2008, Milbau \& Stout 2008). Only a few studies have explored the role of asexual reproduction in the successful invasions of invertebrate taxa (Ting \& Geller 2000, Facon et al. 2003, Stadler et al. 2005), and none have directly tested the hypothesis that asexuality contributes to invasiveness. It seems likely that the capacity for asexual reproduction may mitigate a number of the negative demographic and genetic effects associated with colonization (Roman \& Darling 2007).

One benefit of clonality is the possibility of replication and temporal persistence of especially fit genotypes. For instance, Sherman \& Ayre (2008) have found that fine scale dominance of genotypes in the actiniarian Actinia tenebrosa reflects the expansion of locally adapted clones. On broader scales, the dominance of particular MLGs over large geographic ranges has suggested to some the possibility of general purpose genotypes with high relative fitness across a wide variety of habitat types (Lynch 1984), though recent empirical evidence for this hypothesis is equivocal (Kenny 
1996, Schmid et al. 1999, Van Doninck et al. 2002, Vorburger et al. 2003). Pressure for the maintenance of such genotypes may be particularly strong in marginal habitats such as those populated by Nematostella vectensis (Vorburger et al. 2003).

There is no direct evidence for the competitive superiority of any Nematostella vectensis genotype, although single widespread MLGs have been observed elsewhere in the species range, most notably in England (Pearson et al. 2002, Reitzel et al. 2008). The dominance of 2 clones over multiple sites - including those at Coos Bay and Yaquina Bay, where diversity is high and sexual reproduction appears to be common - suggests that there may be some selective advantage in maintaining their high frequency across the region. It is possible that these lineages exhibit ecological tolerances that confer higher relative fitness in the estuarine habitats frequented by $N$. vectensis on the US west coast. Alternatively, these 2 clones may display a predilection for asexual reproduction. The tendency toward fission may have a genetic basis, as certain populations have been observed with much higher rates of asexual reproduction than others under similar environmental conditions (Reitzel et al. 2008).

In the absence of selective advantage, it is possible that the broad spatial extent of any single MLG may reflect the outcome of stochastic sampling. The genetic composition of the propagule pool colonizing a novel site will be determined by that of the source population, and common MLGs may persist if founding populations expand principally or exclusively by asexual reproduction. Strong founder effects accompanied by asexual reproduction could have yielded dominant clones in newly established populations of Nematostella vectensis on the Pacific coast. If these then served as sources for secondary introductions, clonal dominance would be expected to extend over a broad geographic range. Such dominance of particular genetic types driven by sampling effects has been observed in other invasive taxa (Voisin et al. 2005). However, it is important to note that stochastic and deterministic explanations for clonal dominance may not be mutually exclusive. For instance, the predominance of a single invasive lineage of the brown alga Undaria pinnatifida in Europe is probably due to selective advantage artificially imposed on aquaculture stocks in Asia where the species originated, and not necessarily to selective advantage in the non-native range (Voisin et al. 2005). Thus, although widespread MLGs may exhibit adaptive superiority in those populations from which they originate, they may not necessarily do so across their entire range. Detailed knowledge of invasion history may be required for adequate experimental assessment of the potential selective advantage of widespread MLGs.

\section{Dispersal and range expansion of Nematostella vectensis}

Connectivity between estuarine populations may be limited by the geographic and ecological boundaries separating estuarine habitats (Bilton et al. 2002). Numerous genetic studies of both benthic invertebrates (Perrin et al. 2004, Virgilio \& Abbiati 2004, Schmidt et al. 2006) and coastal fish taxa (Pampoulie et al. 2004, Watts \& Johnson 2004, Bradbury et al. 2008) bear out this prediction, revealing significant genetic differentiation between estuarine populations, in many cases despite the presence of potentially dispersive larval forms. Empirical evidence, thus, suggests that estuarine taxa, particularly those lacking long-lived planktonic larvae, are likely to exhibit marked genetic structure as a result of limited gene flow between populations, with corresponding increases in the potential for local adaptation and limitations to the possibility of range expansion. Human-mediated dispersal could significantly alter these dynamics, however. For instance, Pettengill et al. (2007) have observed only very slight genetic differentiation between widely separated populations of the invasive, dispersal-limited polychaete Hydroides elegans, and suggest that frequent anthropogenic transport of adults and larvae may mitigate natural limits to population connectivity. Similarly, oyster farming probably contributes substantially to the regional expansion of the invasive gastropod Ocinebrellus inornatus in France, despite the lack of a dispersive larval phase (Martel et al. 2004).

The association of Nematostella vectensis with human transport vectors results in patterns of range expansion and genetic connectivity that are unexpected given observed limits to natural dispersal (Reitzel et al. 2008). It is highly unlikely that either of the 2 most dominant clones observed in the current study arose more than once $\left(p_{\text {gen }}=0.000214\right.$ for Clone $1, \mathrm{p}_{\text {gen }}=5.79 \times 10^{-5}$ for Clone 2), and their wide distribution must then result from dispersal between embayments. Thus, their discontinuous geographic distribution indicates gene flow occurs between populations separated by over $1600 \mathrm{~km}$ (San Juan Islands to Tomales Bay, the maximum extent of Clone 2; see Fig. 2).

Genetic studies consistently reveal high levels of differentiation between Nematostella vectensis populations, even those separated by only tens of meters (Darling et al. 2004, Reitzel et al. 2008), and experimental studies of invertebrate dispersal within estuaries have revealed that $N$. vectensis rarely colonizes novel sites within embayments where populations are already established (Stocks \& Grassle 2001). In the present study, pairwise $F_{\mathrm{ST}}$ values between some populations are extremely high, even when repeated clonal 
genotypes are removed from the analysis (Table 4), and the frequency of shared clones is low between neighboring sites (Table 3). Since planulae are produced sexually, the only possible explanation for the broad geographic range of $N$. vectensis clones is the dispersal of adult polyps, or fragments of adult polyps, despite the sessile nature of these forms.

Although we find anthropogenic transport to be the most likely explanation for the broad extent of clonal genotypes, it should be noted that rafting presents a plausible alternative. Nematostella vectensis polyps occasionally cling to epifaunal substrates (J. Darling \& A. Reitzel pers. obs.), and so may associate with marsh grass or algal rafts. Connectivity between populations of many coastal invertebrates with limited dispersal capacity may be mediated by rafting (Thiel \& Gutow 2005), and observations of some species suggest that this mechanism may result in dispersal distances of many hundreds of kilometers (McCormick et al. 2008). In addition, some studies indicate that both anthropogenic transport and rafting together may contribute to the dispersal of certain taxa (Watts et al. 1998). As both mechanisms provide opportunities for long distance dispersal events and broad increases in geographic range, their effects may be difficult to distinguish. However, in the case of $N$. vectensis we find the rafting hypothesis less compelling than the hypothesis of anthropogenic transport for several reasons. First, frequent rafting results in surprisingly low genetic differentiation within regional populations (Dias et al. 2006), a pattern not observed in $N$. vectensis. In addition, the conspicuous genetic differentiation (and lack of shared MLGs) between Gray's Harbor and Willapa Bay suggests that dispersal vectors for $N$. vectensis are episodic and idiosyncratic, and do not necessarily connect estuaries in close geographic proximity. Finally, the direct dispersal of clonal propagules between San Juan Island and Humboldt Bay, without colonization of intervening habitat, is a pattern that seems difficult to explain based on a current-driven dispersal model.

Ballast water is commonly cited as a favored means of anthropogenic dispersal by many coastal and estuarine invasive species (Ruiz et al. 2000, Watts \& Johnson 2004, Wonham \& Carlton 2005). However, this vector seems unlikely in the case of Nematostella vectensis. Not only are adult anemones generally infaunal, but they are typically found in habitats where their entrainment in ballast water tanks would be improbable. Dispersal propagules are much more likely to travel as components of fouling communities, on recreational watercraft or other equipment (e.g. waders, fishing gear). N. vectensis polyps have an impressive adhesive quality (J. Darling \& A. Reitzel pers. obs.) and are capable of passively attaching to most surfaces. High thermal and salinity tolerances, combined with resistance to starvation and desiccation (Darling et al. 2004), could enable propagules to persist for many days outside of their natural environments.

Small scale intra-coastal vectors may play important roles in driving the range expansion of many invasive species (Wonham \& Carlton 2005). A recent study of Elkhorn Slough, California, revealed the presence of numerous invasive taxa present elsewhere along the west coast, despite the absence of any commercial ports (Wasson et al. 2001), and fouling of recreational boats is probably a major vector for the movement of species between such habitats (Floerl \& Inglis 2005). Fouling has been implicated in the global expansion of numerous invasive taxa, including crustaceans (Zardus \& Hadfield 2005, Otani et al. 2007), bryozoans (Marchini et al. 2007), mollusks (Ricciardi 1998) and tunicates (Bullard et al. 2007). We suggest that this vector may be playing a central role in the expansion of the range of Nematostella vectensis in the eastern Pacific Ocean.

\section{Conclusions}

The broad geographic distribution of multiple MLGs reveals that transport of adult Nematostella vectensis must be frequent enough to confer connectivity between multiple embayments throughout the region, thus overcoming documented natural limits to dispersal and confounding expectations for genetic and demographic patterns within this species. If adult anemones are more likely than planulae to be associated with human transport vectors, which would certainly hold true in the case of fouling, then asexual reproduction may provide the most efficient mechanism for the production of dispersive propagules, and could result in broad distributions. The high frequency with which estuarine taxa are dispersed by anthropogenic vectors, along with the facultative asexuality exhibited by many such species, suggests that the patterns observed in $N$. vectensis may be reflected in other species, both introduced and native.

Acknowledgements. The authors thank Shawn Arrellano, Bill Fields, Tammy McGovern and John Chapman for providing Nematostella vectensis specimens from some locations used in this study. Kenneth Oswald, US Environmental Protection Agency (EPA), and 3 anonymous reviewers provided helpful comments on earlier versions of this manuscript. A.M.R. was funded by EPA STAR and the Beacon Institute for Rivers and Estuaries. A.K. is an independent contractor to the EPA. This work was supported in part through a Regional Applied Research Effort (RARE) with EPA Regions 9 and 10. 


\section{LITERATURE CITED}

Arnaud-Haond S, Belkhir K (2007) GENCLONE: a computer program to analyse genotypic data, test for clonality and describe spatial clonal organization. Mol Ecol Notes $7: 15-17$

Ayre DJ (1984) The effects of sexual and asexual reproduction on geographic variation in the sea anemone Actinia tenebrosa. Oecologia 62:222-229

Belkhir K, Borsa P, Chikhi L, Raufaste N, Bonhomme F (2004) GENETIX 4.05, logiciel sous Windows ${ }^{\mathrm{TM}}$ pour la génétique des populations. Laboratoire Génome, Populations, Interactions, Université de Montpellier, Montpellier

Bilton DT, Paula J, Bishop JDD (2002) Dispersal, genetic differentiation and speciation in estuarine organisms. Estuar Coast Shelf Sci 55:937-952

Bradbury IR, Campana SE, Bentzen P (2008) Low genetic connectivity in an estuarine fish with pelagic larvae. Can J Fish Aquat Sci 65:147-158

Bullard SG, Lambert G, Carman MR, Byrnes J and others (2007) The colonial ascidian Didemnum sp. A: current distribution, basic biology and potential threat to marine communities of the northeast and west coasts of North America. J Exp Mar Biol Ecol 342:99-108

Burns JH (2008) Demographic performance predicts invasiveness of species in the Commelinaceae under high-nutrient conditions. Ecol Appl 18:335-346

Carlton J (2001) Introduced species in U.S. coastal waters: environmental impacts and management priorities. Pew Oceans Commission, Arlington, VA

Carlton JT, Geller JB (1993) Ecological roulette: the global transport of nonindigenous marine organisms. Science 261:78-82

Cohen AN, Carlton JT (1998) Accelerating invasion rate in a highly invaded estuary. Science 279:555-558

> Darling JA, Reitzel AM, Finnerty JR (2004) Regional population structure of a widely introduced estuarine invertebrate: Nematostella vectensis Stephenson in New England. Mol Ecol 13:2969-2981

> Darling JA, Reitzel AM, Finnerty JR (2006) Characterization of microsatellite loci in the widely introduced estuarine anemone Nematostella vectensis. Mol Ecol Notes 6: 803-805

Dias GM, Duarte LFL, Solferini VN (2006) Low genetic differentiation between isolated populations of the colonial ascidian Symplegma rubra Monniot, C. 1972. Mar Biol 148:807-815

Facon B, Pointier JP, Glaubrecht M, Poux C, Jarne P, David P (2003) A molecular phylogeography approach to biological invasions of the New World by parthenogenetic Thiarid snails. Mol Ecol 12:3027-3039

Floerl O, Inglis GJ (2005) Starting the invasion pathway: the interaction between source populations and human transport vectors. Biol Invasions 7:589-606

Foster NL, Baums IB, Mumby PJ (2007) Sexual vs. asexual reproduction in an ecosystem engineer: the massive coral Montastraea annularis. J Anim Ecol 76:384-391

Goudet J (2001) FSTAT (Version 1.2), a computer program to calculate $F$-statistics. J Hered 86:485-486

- Grosholz E (2002) Ecological and evolutionary consequences of coastal invasions. Trends Ecol Evol 17:22-27

- Hand C, Uhlinger KR (1992) The culture, sexual and asexual reproduction, and growth of the sea anemone Nematostella vectensis. Biol Bull (Woods Hole) 182: 169-176

Hand C, Uhlinger KR (1994) The unique, widely distributed, estuarine sea anemone, Nematostella vectensis Stephen- son-a review, new facts, and questions. Estuaries 17:501-508

Jackson JBC, Buss LW, Cook RE (1985) Population biology and evolution of clonal organisms. Yale University Press, New Haven, CT

- Kenny NT (1996) A test of the general-purpose genotype hypothesis in sexual and asexual Erigeron species. Am Midl Nat 136:1-13

> Levin LA (2006) Recent progress in understanding larval dispersal: new directions and digressions. Integr Comp Biol 46:282-297

Lynch M (1984) Destabilizing hybridization, general-purpose genotypes and geographic parthenogenesis. Q Rev Biol 59:257-290

Marchini A, Cunha MR, Occhipinti-Ambrogi A (2007) First observations on bryozoans and entoprocts in the Ria de Aveiro (NW Portugal) including the first record of the Pacific invasive cheilostome Tricellaria inopinata. PSZN I: Mar Ecol 28:154-160

> Martel C, Viard F, Bourguet D, Garcia-Meunier P (2004) Invasion by the marine gastropod Ocinebrellus inornatus in France. II. Expansion along the Atlantic coast. Mar Ecol Prog Ser 273:163-172

McCormick TB, Buckley LM, Brogan J, Perry LM (2008) Drift macroalgae as a potential dispersal mechanism for the white abalone Haliotis sorenseni. Mar Ecol Prog Ser 362:225-232

Milbau A, Stout JC (2008) Factors associated with alien plants transitioning from casual, to naturalized, to invasive. Conserv Biol 22:308-317

Miller KJ, Ayre DJ (2004) The role of sexual and asexual reproduction in structuring high latitude populations of the reef coral Pocillopora damicornis. Heredity 92: $557-568$

Otani M, Oumi T, Uwai S, Hanyuda T, Prabowo RE, Yamaguchi T, Kawai H (2007) Occurrence and diversity of barnacles on international ships visiting Osaka Bay, Japan, and the risk of their introduction. Biofouling 23:277-286

> Pampoulie C, Gysels ES, Maes GE, Hellemans B, Leentjens V, Jones AG, Volckaert FAM (2004) Evidence for fine-scale genetic structure and estuarine colonisation in a potential high gene flow marine goby (Pomatoschistus minutus). Heredity 92:434-445

Pearson CVM, Rogers AD, Sheader M (2002) The genetic structure of the rare lagoonal sea anemone, Nematostella vectensis Stephenson (Cnidaria; Anthozoa) in the United Kingdom based on RAPD analysis. Mol Ecol 11:2285-2293

> Perrin C, Wing SR, Roy MS (2004) Effects of hydrographic barriers on population genetic structure of the sea star Coscinasterias muricata (Echinodermata, Asteroidea) in the New Zealand fiords. Mol Ecol 13:2183-2195

Pettengill JB, Wendt DE, Schug MD, Hadfield MG (2007) Biofouling likely serves as a major mode of dispersal for the polychaete tubeworm Hydroides elegans as inferred from microsatellite loci. Biofouling 23:161-169

Reitzel AM, Burton PM, Krone C, Finnerty JR (2007) Comparison of developmental trajectories in the starlet sea anemone Nematostella vectensis: embryogenesis, regeneration, and two forms of asexual fission. Invertebr Biol 126:99-112

Reitzel AM, Darling JA, Sullivan JC, Finnerty JR (2008) Global population genetic structure of the starlet anemone Nematostella vectensis: evidence for multiple independent introductions and implications for conservation policy. Biol Invasions 10:1197-1213

> Ricciardi A (1998) Global range expansion of the Asian mussel Limnoperna fortunei (Mytilidae): another fouling 
threat to freshwater systems. Biofouling 13:97-106

Roman J, Darling JA (2007) Paradox lost: genetic diversity and the success of aquatic invasions. Trends Ecol Evol 22:454-464

Rousset F (2008) GENEPOP ‘007: a complete reimplementation of the genepop software for Windows and Linux. Mol Ecol Resources 8:103-106

Ruesink JL, Collado-Vides L (2006) Modeling the increase and control of Caulerpa taxifolia, an invasive marine macroalga. Biol Invasions 8:309-325

Ruiz GM, Fofonoff PW, Carlton JT, Wonham MJ, Hines AH (2000) Invasion of coastal marine communities in North America: apparent patterns, processes, and biases. Annu Rev Ecol Syst 31:481-531

Sakai A, Allendorf FW, Holt JS, Lodge DM and others (2001) The population biology of invasive species. Annu Rev Ecol Syst 32:305-332

Schmid J, Herd S, Hunter PR, Cannon RD and others (1999) Evidence for a general-purpose genotype in Candida albicans, highly prevalent in multiple geographical regions, patient types and types of infection. Microbiology 145: 2405-2413

Schmidt AJ, Toro JE, Chaparro OR (2006) Reproductive patterns and their influence on the population genetics of sympatric species of the genus Crepidula (Gastropoda: Calyptraeidae). J Shellfish Res 25:371-378

Shaw PW (1991) Effects of asexual reproduction on population structure of Sagartia elegans (Anthozoa, Actiniaria). Hydrobiologia 216-217:519-525

Sherman CDH, Ayre DJ (2008) Fine-scale adaptation in a clonal sea anemone. Evolution 62:1373-1380

Stadler T, Frye M, Neiman M, Lively CM (2005) Mitochondrial haplotypes and the New Zealand origin of clonal European Potamopyrgus, an invasive aquatic snail. Mol Ecol 14:2465-2473

Stocks KI, Grassle JF (2001) Effects of microalgae and food limitation on the recolonization of benthic macrofauna into in situ saltmarsh-pond mesocosms. Mar Ecol Prog Ser 221:93-104

Stoddart JA (1984) Genetical structure within populations of the coral Poeillopora damieornis. Mar Biol 81:19-30

Thiel M, Gutow L (2005) The ecology of rafting in the marine environment. II. The rafting organisms and community. Annu Rev Oceanogr Mar Biol 43:279-418

Ting JH, Geller JB (2000) Clonal diversity in introduced populations of an Asian sea anemone in North America. Biol Invasions 2:23-32

> Van Doninck K, Schon I, De Bruyn L, Martens K (2002) A gen-

Editorial responsibility: Richard Osman,

Edgewater, Maryland, USA eral purpose genotype in an ancient asexual. Oecologia 132:205-212

Virgilio M, Abbiati M (2004) Habitat discontinuity and genetic structure in populations of the estuarine species Hediste diversicolor (Polychaeta: Nereididae). Estuar Coast Shelf Sci 61:361-367

> Voisin M, Engel CR, Viard F (2005) Differential shuffling of native genetic diversity across introduced regions in a brown alga: aquaculture vs. maritime traffic effects. Proc Natl Acad Sci USA 102:5432-5437

> Vorburger C, Sunnucks P, Ward SA (2003) Explaining the coexistence of asexuals with their sexual progenitors: no evidence for general-purpose genotypes in obligate parthenogens of the peach-potato aphid, Myzus persicae. Ecol Lett 6:1091-1098

> Wasson K, Zabin CJ, Bedinger L, Diaz MC, Pearse JS (2001) Biological invasions of estuaries without international shipping: the importance of intraregional transport. Biol Conserv 102:143-153

- Watts RJ, Johnson MS (2004) Estuaries, lagoons and enclosed embayments: habitats that enhance population subdivision of inshore fishes. Mar Freshw Res 55:641-651

> Watts PC, Thorpe JP, Taylor PD (1998) Natural and anthropogenic dispersal mechanisms in the marine environment: a study using cheilostome Bryozoa. Philos Trans R Soc Lond B Biol Sci 353:453-464

Whitaker K (2006) Genetic evidence for mixed modes of reproduction in the coral Pocillopora damicornis and its effect on population structure. Mar Ecol Prog Ser 306: 115-124

Williams SL, Grosholz ED (2008) The invasive species challenge in estuarine and coastal environments: marrying management and science. Estuar Coast 31:3-20

Wonham MJ, Carlton JT (2005) Trends in marine biological invasions at local and regional scales: the Northeast Pacific Ocean as a model system. Biol Invasions 7:369-392

Wonham MJ, Carlton JT, Ruiz GM, Smith LD (2000) Fish and ships: relating dispersal frequency to success in biological invasions. Mar Biol 136:1111-1121

> Wright JT, Davis AR (2006) Demographic feedback between clonal growth and fragmentation in an invasive seaweed. Ecology 87:1744-1754

Zardus JD, Hadfield MG (2005) Multiple origins and incursions of the Atlantic barnacle Chthamalus proteus in the Pacific. Mol Ecol 14:3719-3733

Zilberberg C, Sole-Cava AM, Klautau M (2006) The extent of asexual reproduction in sponges of the genus Chondrilla (Demospongiae: Chondrosida) from the Caribbean and the Brazilian coasts. J Exp Mar Biol Ecol 336:211-220

Submitted: October 21, 2008; Accepted: January 8, 2009 Proofs received from author(s): March 23, 2009 